\title{
AN INTEGRATED REVERSE ENGINEERING APPROACH FOR ACCURACY CONTROL OF FREE-FORM OBJECTS
}

\begin{abstract}
Computer-aided tools help in shortening and eradicating numerous repetitive tasks that reduces the gap between digital model and actual product. Use of these tools assists in realizing free-form objects such as custom fit products as described by a stringent interaction with the human body. Development of such a model presents a challenging situation for reverse engineering (RE) which is not analogous with the requirement for generating simple geometric models. Hence, an alternating way of producing more accurate three-dimensional models is proposed. For creating accurate 3D models, point clouds are processed through filtering, segmentation, mesh smoothing and surface generation. These processes help in converting the initial unorganized point data into a 3D digital model and simultaneously influence the quality of model. This study provides an optimum balance for the best accuracy obtainable with maximum allowable deviation to lessen computer handling and processing time. A realistic non trivial case study of free-form prosthetic socket is considered. The accuracy obtained for the developed model is acceptable for the use in medical applications and FEM analysis.
\end{abstract}

\section{Introduction}

Conventionally, the design and development of a product initiates in virtual environment with three-dimensioning CAD modelling. The objective is to provide an improved and accurate products to the society [1]. Often, replication of intricate profiles with varying design shapes is a challenging task using CAD tools. Reverse engineering (RE) system helps in creating a 3D CAD model using point data of an existing physical object. Numerous applications of RE include replication of an object, when actual drawings or digital model does not exist; when testing

\footnotetext{
${ }^{1}$ Malaviya National Institute of Technology, Jaipur, Rajasthan-302017, India. Email: vimalpthk@gmail.com
} 
and alterations are necessary for improvement of new product or a re-design of a part or where the geometry is complex and challenging for direct modelling in a CAD system. An additional imperative application of $\mathrm{RE}$ is in the medical field to produce free-form features for generating custom-fit products [2-8].

$\mathrm{RE}$ begins with acquisition of $3 \mathrm{D}$ point clouds from the external surface of an actual product. Various methods are available for obtaining different data shape [9-11] with each one of these works on a different principle to acquire the point data from the part surface, usually known as digitalization. For data acquisition, common methods used are the contact-based coordinate measuring machine (CMM) and contactless laser scanning $[9,12]$. The touch probe method has a high accuracy, usually performed with a touch probe CMM. However, CMM method is timeconsuming as it considers the point-to-point measurement. In contrast, laser scanner provides the advantage of digitalizing extremely soft materials such as human skin with high speed.

Traditionally, common methods used for constructing digital human body models or free-form shapes are based on structured light pattern and 3D scanner methods. The prime significance of these systems are the digitization time, capturing an accurate profile of a surface and ease of use. The problem associated with these devices is concerned with missing data points, due to the occlusion and inaccurate surface generation because of the potential reflection of laser from a shiny surface $[10,11]$.

The primary concern in developing 3D models using RE systems is the inconvenience in handling millions of point data acquired by digitization of a physical object [13]. The second problem arises in creation of meshes which best explain the part surface [14]. Finally, it is imperative for the RE tools to not only develop a complete digital model, but should also acquire the original design shape and geometry $[15,16]$.

3D models with free-form profiles are extensively used in medical applications such as surgery planning, customized inserts and biomechanical work. In the same context, the design and development of prosthesis socket is a challenge due to the complex geometry of the stump which differs from one amputee to another. The accuracy of the developed 3D model is of utmost importance for the outcome of the result, particularly when different software process the captured point data. So, it is indispensable to examine the accuracy of the developed digital model with reference to the actual physical model. Several RE software tools are available that suits the requirements needed by design personnel and operators. Prior using difficult mathematical approximations, they attempt to obtain the desired accuracy of 3D models by regulating various key factors through continuous approximations using commercially available CAD application tools.

This study proposes an integrated methodology for measuring the finest accuracy of 3D models generated by RE employing commercial CAD tools. Determination of key factors and how they influence the $3 \mathrm{D}$ model accuracy from RE is evaluated. In order to guarantee digital model accuracy, the correct use of surface 
reconstruction process used in RE is of vital importance. The prime objective of the current work is to investigate the deviation between dimensional and geometric digital models of a prosthesis socket using various approaches for point data processing. It should be clear that the resulted deviations illustrate the effects of the applied CAD systems settings on the result of a specific operation (smoothing, filtering, etc.). Each operation performed on the point cloud, mesh polygons, increases the differences between the processed data and the initial digitizing results. The operation parameters should therefore be carefully chosen. The study was performed using two dissimilar CAD tools to reconstruct a free-form intricate profile. Finally, a comparative analysis of the outcome of results was performed using a 3D metrology interface.

\section{Materials and Methods}

\subsection{Study Model}

The present study focuses on accurate 3D surface generation of a complex profile. This free-form surface is generated from a Plaster of Paris (PoP) socket model of an amputee. The external dimensions of the socket are $105 \mathrm{~mm}$ (maximum diameter) with a height of $252 \mathrm{~mm}$. The complete PoP socket model and 3D scanning arrangement are shown in Fig. 1.

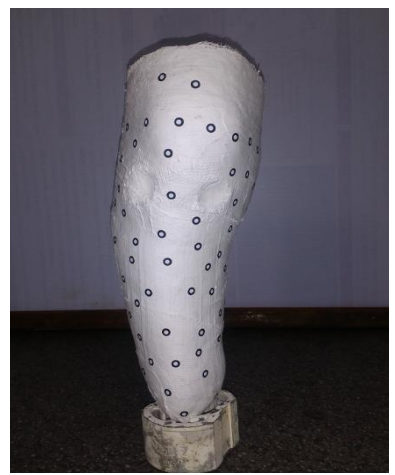

(a)

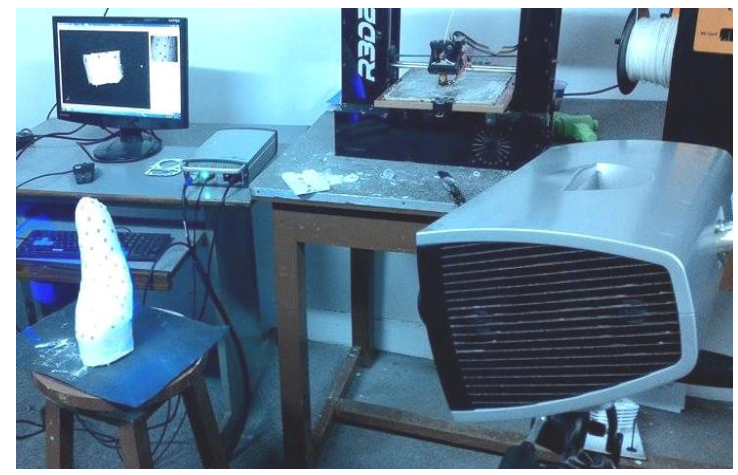

(b)

Fig. 1. The Plaster of Paris socket (a), 3D scanning arrangement (b)

\subsubsection{Point clouds digitization}

The case study was scanned using a non-contact blue light scanner (Steinbichler's COMET L3D) [17]. The mean acquisition rate of COMET L3D scanner is about 50,000 points per second. The version used in this study for data acquisition has a resolution of $1 \mathrm{Mpx}$ and $1170 \times 880$ pixels. The complete acquisition of 
the case study takes about 15 scans, which are taken from different orientations. The socket was placed on a rotary table which makes the scanning process more efficient and faster. The complete digitization process for handling the point clouds was controlled by the 3D scanner software (COMET PLUS). To change the point of view between one scan and the next one, the part was fixed in the working volume and the scanner location was changed. No additional data processing was needed, since the RE software merges multiple scans in one point cloud either automatically or by manually selecting $\mathrm{N}$ points. For effective scanning and identification of previous scans, tie points are placed on the socket surface uniformly. The 3D point cloud was exported in IGES format and the raw data of the socket consists of 11,585 points.

\subsubsection{RE tools application}

RE systems goal is to transform unorganized 3D point clouds into a surface replica with desired precision and accuracy. There are generally two segments available in these systems: one module converts the raw data into a triangle mesh and second module reconstruct digital surface model from a triangle mesh file. The present study employed two different CAD tools: CATIA V5R16 and SolidWorks 2010. For CATIA study, mesh file was formed using the module Digitized Shape Editor and the surface model was reconstructed using Quick Surface Reconstruction module and for SolidWorks Scanto3D modules were used. After data capturing, three important steps include:

Step 1 - Post-processing of raw point data. The outliers associated with point cloud data were removed followed with the use of adaptive and homogeneous filtering techniques applied with different percentages. The initial point data captured comprise all the geometric features of the object. The initial raw points consist of higher proportion of noise produced as a result of the 3D scanning process. Consequently, huge amount of data size is produced and for effective handling and processing of this data, a suitable filtering technique is applied which results in reducing the redundant points without losing object original geometry.

Step 2 - Development of triangle meshes and processing. The development of triangle meshes is popularly known as tessellation. It is a process to build triangles by joining three neighbouring points and replicates the same procedure until a network is formed to create a definite, lucid and consistent triangulated surface [18]. In general, the initial raw mesh consists of sharp boundaries and non-manifold vertices, all these discrepancies need to be rectified to guarantee accurate surface generation. Further, it is essential that the meshes are cleaned and refined. The residual unwanted triangle meshes removed and created holes are filled. Occasionally, the triangle meshes are extremely dense which enhances difficulty in handling and processing the file data. The solution to this problem is re-meshing and decimation of the mesh file. Smoothing the mesh, moreover, helps in improving the accuracy of the generated surface model. 
Step 3 - Generation of surface model and feature identification. The accuracy of socket surface model was analysed using the parameters including mean deviations (AD), maximum deviation and standard deviation. Three different techniques were employed for the surface reconstruction from a triangular mesh file: feature recognition, surface fitting and NURBS surface patching. Subsequently, for regular features or prismatic profiles, not many software applications are available that allow semi or fully-automated procedure for recognition of various features, which highly depends on the intricacy of the shape. Several individual surfaces are linked resulting in an approximate global surface with automatic creation of arbitrary topology. The surface fitting technique was not applied in the current work. Since the development of each surface fit to characterize the complete surface of a part requires sufficient user expertise that will definitely reflect in the outcome of the final result.

\subsection{CATIA Methodology}

First part of the current work was realized using the CATIA software. The organization of the performed process is shown in Figure 2. It includes critical parameters of the filtering process, the mesh generation process and the settings applicable for smoothing process prior to surface reconstruction. For free-form geometry, it is essential to carefully remove all outlier points manually after choosing initial point data of the concerned region. The mesh file $\mathrm{W}$ signifies the default procedure employed without using any of filtering or smoothing techniques prior to surface reconstruction.

\subsubsection{Filtering technique effect}

The Digitized Shape Editor module was used for the reduction of noise and redundant points by using two different types of filtering criteria. The use of the adaptive filtering causes a reduction in the point data which is based on a chord height deviation analysis criteria. This technique helps in removing points from flat zones but preserves data close to the edges, boundaries and high curvature zones. The 3D point cloud was exported and the raw data of the socket model consisted of 11,585 points. Following results for number of faces, maximum deviation and mean deviation were obtained automatically after performing the individual filtering processes. The software provides deviation value of model in comparison to actual model without performing any individual processes.

The use of homogeneous filtering allows a uniform reduction in the point cloud data. Different point filtering percentages $(15 \%, 22 \%, 30 \%$ and $45 \%)$ were applied to point data using both the filtering techniques. The default value taken by the software for filtering was $22 \%$ which was used as the control for comparison purpose. The resultant files were studied and examined using reduced points (\%), number of faces, reduction in mean and maximum deviation. The best results were 


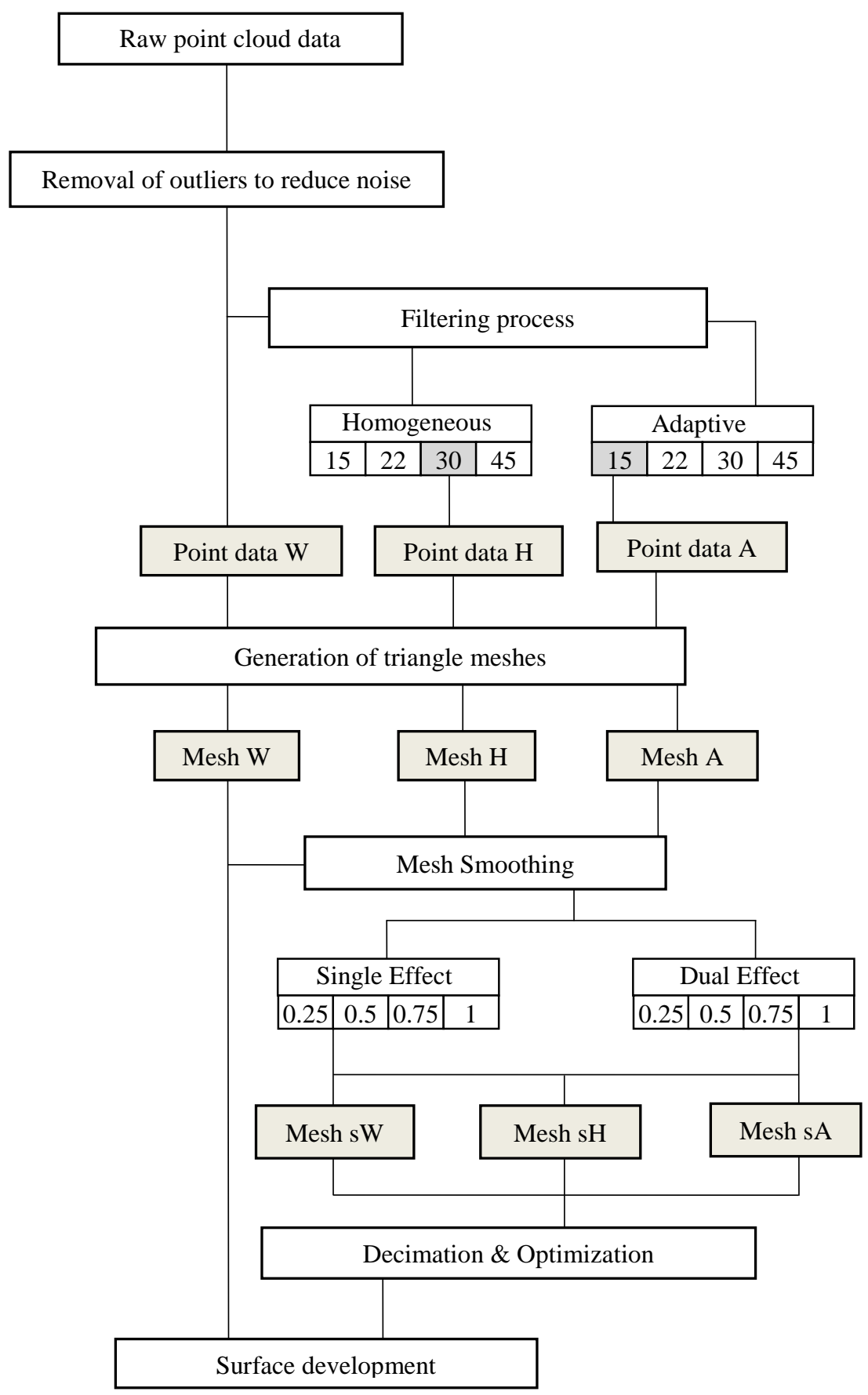

Fig. 2. Methodology for CATIA study 
provided by the homogeneous filtering technique for mesh $(\mathrm{H})$ with $30 \%$ of reduced points with a reduction in maximum deviation of $55.27 \%$ and mean deviation $25.67 \%$ (see Table 1). For the adaptive filter, mesh (A) with $15 \%$ of reduced points shows best results with a reduction in maximum deviation of $72.31 \%$ and in mean deviation $35.76 \%$ (Table 1).

Table 1.

Filtering results for point data using homogeneous filter and adaptive filter

\begin{tabular}{|c|c|c|c|c|c|c|c|c|c|}
\hline \multicolumn{2}{|c|}{} & \multicolumn{5}{|c|}{ Homogeneous } & \multicolumn{4}{c|}{ Adaptive } \\
\hline Reduction & $0 \%$ & $15 \%$ & $22 \%$ & $30 \%$ & $45 \%$ & $15 \%$ & $22 \%$ & $30 \%$ & $45 \%$ \\
\hline $\begin{array}{c}\text { Number } \\
\text { of faces }\end{array}$ & 124 & 108 & 122 & 101 & 94 & 120 & 115 & 105 & 87 \\
\cline { 2 - 10 } $\begin{array}{c}\text { Max. } \\
\text { deviation }\end{array}$ & 1.570 & $-12.90 \%$ & $-1.61 \%$ & $-18.55 \%$ & $-24.19 \%$ & $-3.22 \%$ & $-7.26 \%$ & $-15.32 \%$ & $-29.84 \%$ \\
\hline & $-35.09 \%$ & $-4.71 \%$ & $-55.27 \%$ & $2.49 \%$ & $-72.31 \%$ & $-34.12 \%$ & $-12.43 \%$ & $-25.13 \%$ \\
\hline $\begin{array}{c}\text { Mean. } \\
\text { deviation }\end{array}$ & 0.950 & 0.760 & 0.810 & 0.601 & 0.851 & 0.310 & 0.833 & 0.900 & 0.882 \\
\cline { 2 - 9 } & $-20.05 \%$ & $-14.76 \%$ & $-25.76 \%$ & $-10.45 \%$ & $-35.76 \%$ & $-12.35 \%$ & $-5.31 \%$ & $-7.13 \%$ \\
\hline
\end{tabular}

\subsubsection{Mesh smoothing process analysis}

The prime objective of mesh smoothing process is to enhance the accuracy of the reconstructed surface, which can be realized by the operator input and depicts global effects. There are two techniques available (single effect or the dual effect) for mesh smoothing from which the consumer can choose either of the ones. The importance of the single effect is that it will rub out the sharp edges present in the mesh resulting in the reduction of the volume of the object (shrinkage in the direction of the center of gravity of the object). The second technique lessens the distance between the surface and outliers, furthermore it also reduces the deletion of minor internal radius. Thus, results for maximum and mean deviation were obtained automatically after performing the individual smoothening processes using the smoothing module through the software.

For the analysis of the used smoothing techniques, both single and dual effects parameters used were $0.25,0.5,0.75$ and 1 generating mesh $\mathrm{W}$, mesh $\mathrm{H}$ and mesh A. Mesh W was realized without using any of the filtering technique. The developed meshes were analysed using the percentage of reduced points, the number of faces, and maximum and mean deviation. The finest accuracy results were achieved for smoothing technique used in mesh W (without any filtering). Best result obtained using double effect smoothing, 0.25 parameter for mesh $\mathrm{W}$ reduces the maximum and mean deviation to $62.15 \%$ and $25.71 \%$ respectively. For the mesh A (adaptive filter 15\%), best results were obtained for single effect 0.75 smoothing with reduction of about $17.3 \%$ as maximum deviation and $25.5 \%$ as the mean deviation. Finally, for $30 \%$ homogeneous mesh $\mathrm{H}$, best results were coming for the single effect smoothing with factor of 0.50 . This shows an increment in 
maximum deviation of $7.2 \%$ and decrease in the mean deviation of $9.2 \%$. Table 2 depicts the best outcomes for each of the mesh.

Table 2.

Results obtained after smoothing effect

\begin{tabular}{|c|c|c|c|c|c|c|c|}
\hline & \multicolumn{2}{|c|}{ Mesh W } & \multicolumn{2}{|c|}{ Mesh A } & \multicolumn{2}{|c|}{ Mesh H } \\
\hline & & $\begin{array}{c}\text { Max. } \\
(1.5 \mathrm{~mm})\end{array}$ & $\begin{array}{c}\text { Mean } \\
(0.9 \mathrm{~mm})\end{array}$ & $\begin{array}{c}\text { Max. } \\
(0.425 \mathrm{~mm})\end{array}$ & $\begin{array}{c}\text { Mean } \\
(0.31 \mathrm{~mm})\end{array}$ & $\begin{array}{c}\text { Max. } \\
(0.702 \mathrm{~mm})\end{array}$ & $\begin{array}{c}\text { Mean } \\
(0.601 \mathrm{~mm})\end{array}$ \\
\hline \multirow{8}{*}{$\begin{array}{l}\stackrel{0}{00} \\
\stackrel{0}{\infty}\end{array}$} & \multirow{2}{*}{0.25} & 1.323 & 0.719 & 0.392 & 0.292 & 0.774 & 0.576 \\
\hline & & $-11.8 \%$ & $-20.15 \%$ & $-7.76 \%$ & $-5.81 \%$ & $10.23 \%$ & $-4.22 \%$ \\
\hline & \multirow{2}{*}{0.50} & 1.174 & 0.830 & 0.451 & 0.302 & 0.752 & 0.546 \\
\hline & & $-21.73 \%$ & $-7.74 \%$ & $6.12 \%$ & -2.43 & $7.2 \%$ & $-9.2 \%$ \\
\hline & \multirow{2}{*}{0.75} & 1.092 & 0.674 & 0.351 & 0.231 & 0.840 & 0.644 \\
\hline & & $-27.2 \%$ & $-25.06 \%$ & $-17.3 \%$ & $-25.5 \%$ & 19.71 & $7.23 \%$ \\
\hline & \multirow{2}{*}{1.0} & 1.350 & 0.801 & 0.381 & 0.277 & 0.803 & 0.587 \\
\hline & & $-10.0 \%$ & $-11.24 \%$ & $-10.35 \%$ & -18.37 & $14.47 \%$ & $-2.35 \%$ \\
\hline \multirow{8}{*}{$\overline{\tilde{D}}$} & \multirow{2}{*}{0.25} & 0.568 & 0.505 & 0.372 & 0.271 & 0.715 & 0.564 \\
\hline & & $-62.15 \%$ & -43.87 & $-12.47 \%$ & $-12.58 \%$ & 1.86 & $-6.12 \%$ \\
\hline & \multirow{2}{*}{0.50} & 0.782 & 0.593 & 0.447 & 0.320 & 0.772 & 0.614 \\
\hline & & $-47.87 \%$ & $-34.11 \%$ & $2.2 \%$ & $3.1 \%$ & $9.97 \%$ & $2.24 \%$ \\
\hline & \multirow{2}{*}{0.75} & 0.859 & 0.711 & 0.512 & 0.353 & 0.812 & 0.686 \\
\hline & & $-42.73 \%$ & $-22.0 \%$ & $20.47 \%$ & $13.87 \%$ & $15.67 \%$ & $14.21 \%$ \\
\hline & \multirow{2}{*}{1.0} & 1.142 & 0.860 & 0.435 & 0.291 & 0.873 & 0.765 \\
\hline & & $-23.87 \%$ & $-4.44 \%$ & $2.35 \%$ & $-6.13 \%$ & $24.36 \%$ & $27.32 \%$ \\
\hline
\end{tabular}

\subsubsection{Decimation and optimization mesh process}

As the resultant mesh sizes were large, it is better to represent it accurately with less number of triangles. The process of lowering the number of triangle mesh, which makes it suitable for processing and handling of the data, is known as decimation. It can be executed on the whole mesh or on any selected area of the mesh file. There are two types of decimation available, the first is the chordal deviation method and the second is the edge length criterion. However, this study does not consider the decimation process as it can lead to a reduction in accuracy in regions with high curvature, also it may influence the outcome of the results. Next step is to optimize the triangle meshes as this process reallocates the triangles meshes. The usefulness of this process consists in obtaining homogeneity in meshes. This process performs edge split and collapses depending on whether the edge is too long or too short.

The optimization operation has a tendency to change the shape of the digital model. Consequently, this paper takes into consideration the point $\%$ to make a comparison between the initial mesh with the optimized mesh. The outcome of the 
result suggested that best results for mesh $\mathrm{W}$ were obtained for dual effect of 0.25 were $0.875 \mathrm{~mm}$ and $0.069 \mathrm{~mm}$ for the maximum and mean deviation. For mesh $\mathrm{H}$, single smoothing with 0.75 factor presents the best result with a maximum and mean deviation of $1.136 \mathrm{~mm}$ and $0.135 \mathrm{~mm}$ respectively. For mesh A, single effect smoothing with 0.75 shows mean and maximum deviations were $0.113 \mathrm{~mm}$ and $0.748 \mathrm{~mm}$ respectively.

\subsubsection{Surface generation}

The process of surface generation begins with triangle meshes. Generally, the complexity of the free-form structure of socket peripheral can be duplicated through automated reconstruction commands. In this paper, the generation of the freeform surface was accomplished by the automatic setting of Surface Reconstruction module. The parameters that were analysed include output surfaces, the percentage of points within tolerance, maximum and average surface deviation. The key input factors include the average surface deviation and the surface detail. The methodology applied is shown in Fig. 3.

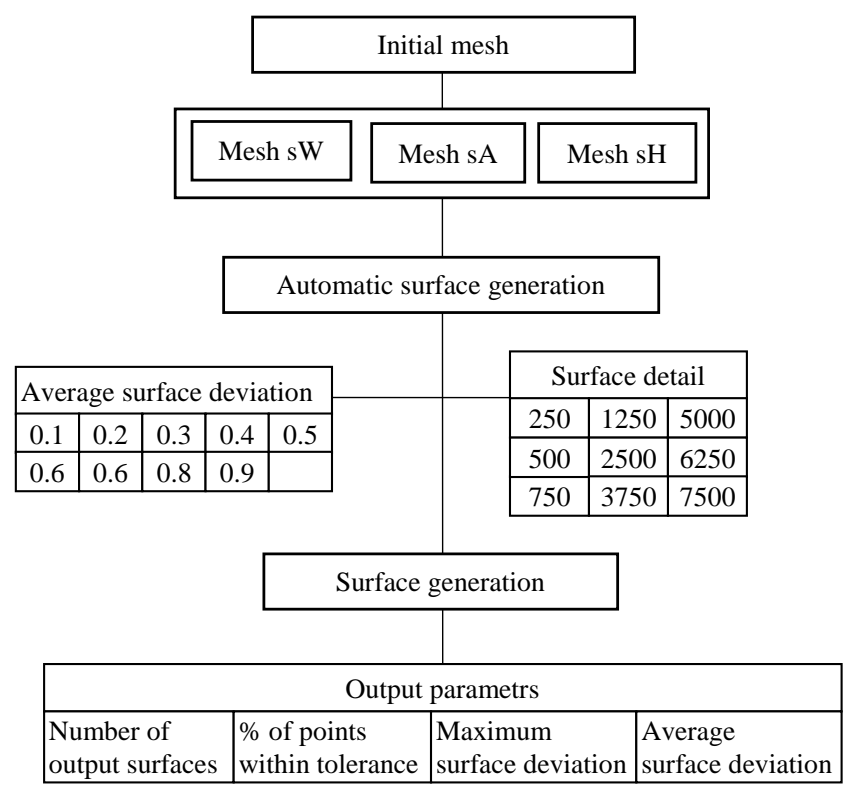

Fig. 3. Methodology applied for surface generation

One important input parameter set by the operator was the average surface deviation to achieve the desired accuracy of the surface generated. The outcome of setting this parameter shows some interesting results (see Fig. 4). At a lesser value, it provides small surface deviation, but in contrast the number of surfaces generated also increases which in turn increases the size of data. 


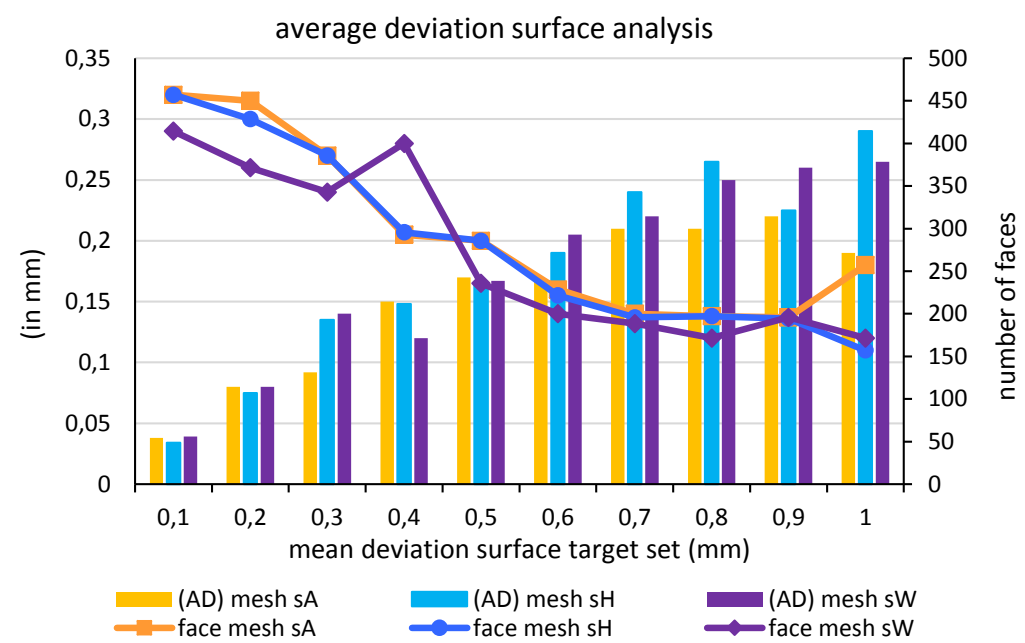

Fig. 4. Plot between mean deviation and number of faces

The effect of another significant parameter, i.e. surface detail, is shown in Fig. 5. With the increase in the surface details from 250 to 7500 , a significant reduction is shown in the maximum and mean surface deviation. The variation shown was more evident up to a surface facet of 1250 , and another noticeable result was observed in the increase in the number of surfaces beyond this value. The surface detail of 1250 appears to be the standard value as beyond which it seems that there was not any significant variation in the results. This means that after this reference value, there does not seem any additional benefits for increasing the refinement.

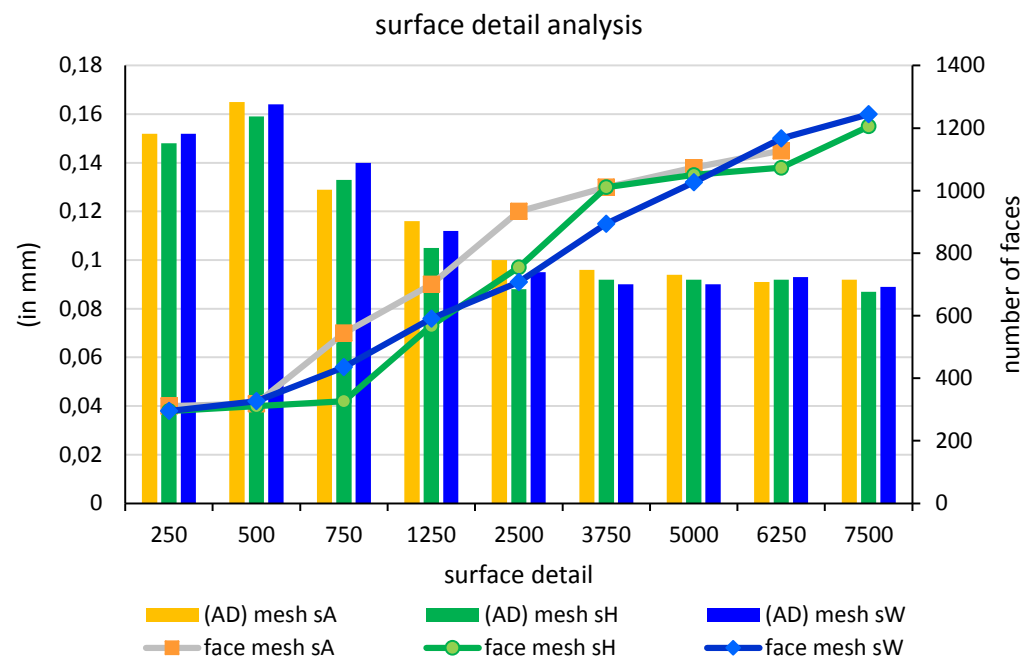

Fig. 5. Plot between mean deviation, surface detail and number of surfaces 


\subsection{Solidworks study}

The second part of this study was performed employing the Solidworks using the ScanTo3D add-in. The practicality of this add-in is that it is easy in use and can be used in an automatic way by simply varying few optional parameters. The performed methodology using solidworks is shown in Fig. 6 and one can see slight difference comparatively to the CATIA software study. The process of removing

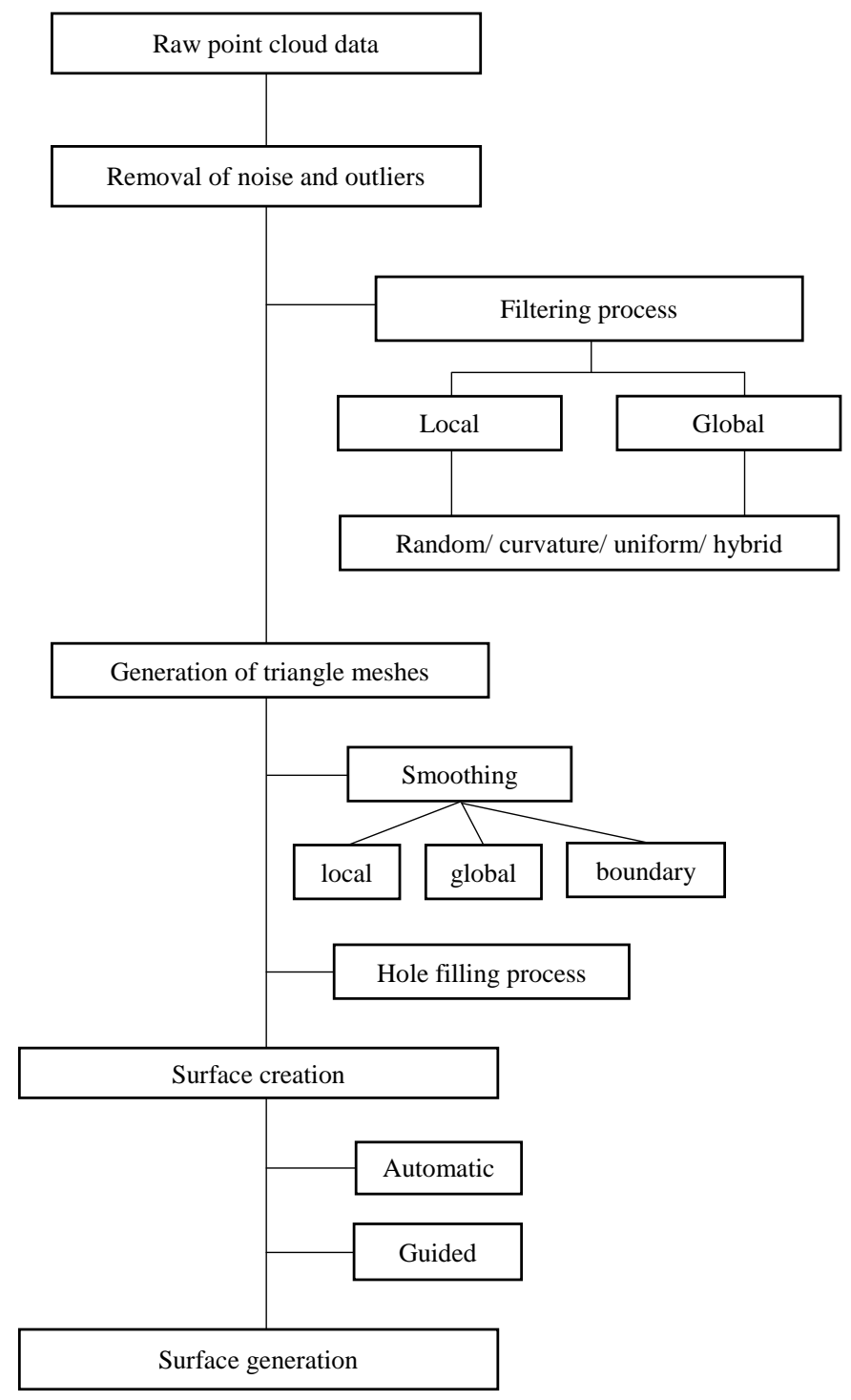

Fig. 6. Proposed methodology for Solidworks study 
outliers and noise is employed on all the point clouds and does not appear to have a significant influence on the overall accuracy as the mean and standard deviation have minimal variation. Next step was to use the process of filtering which will be applied on the entire point clouds. The command used in the software to filter out point clouds was the "simplification" command by employing curvature based, random, uniform and hybrid based criteria. The 3D point cloud was exported and the raw data of the socket model consists of 11,585 points. Following results for number of faces, maximum and min. deviation were obtained automatically after performing the individual filtering processes. The outcome of filter process is reported in Table 3. From the results, it is clear that the curvature based filter and hybrid-based filter have shown significant variation having a reduction factor of $30 \%$ and $15 \%$ respectively. In both the cases, a substantial reduction in the maximum and minimum deviation was witnessed.

Table 3.

Filtering process output for point cloud data

\begin{tabular}{|c|c|c|c|c|c|c|c|}
\hline \multirow{2}{*}{ reduction } & \multirow[b]{2}{*}{$0 \%$} & \multicolumn{3}{|c|}{ Random } & \multicolumn{3}{|c|}{ Curvature } \\
\hline & & $15 \%$ & $30 \%$ & $45 \%$ & $15 \%$ & $30 \%$ & $45 \%$ \\
\hline \multirow{2}{*}{$\begin{array}{l}\text { Number } \\
\text { of faces }\end{array}$} & \multirow{2}{*}{124} & 112 & 103 & 80 & 145 & 118 & 92 \\
\hline & & $-9.68 \%$ & $-16.93 \%$ & $-35.48 \%$ & $16.94 \%$ & $-4.84 \%$ & $-25.81 \%$ \\
\hline \multirow{2}{*}{$\begin{array}{c}\text { Max. } \\
\text { deviation }\end{array}$} & \multirow{2}{*}{1.57} & 1.34 & 0.86 & 3.87 & 1.28 & 0.57 & 3.95 \\
\hline & & $-14.65 \%$ & $-45.22 \%$ & $146.5 \%$ & $-18.47 \%$ & $-63.7 \%$ & $151.6 \%$ \\
\hline \multirow{2}{*}{$\begin{array}{c}\text { Min. } \\
\text { deviation }\end{array}$} & \multirow{2}{*}{-0.65} & -0.85 & -0.98 & -1.97 & -0.68 & -1.27 & -1.03 \\
\hline & & $30.88 \%$ & $50.8 \%$ & $203.07 \%$ & $4.61 \%$ & $95.4 \%$ & $58.5 \%$ \\
\hline \multirow{2}{*}{$\begin{array}{c}\text { Std. } \\
\text { deviation }\end{array}$} & \multirow{2}{*}{0.097} & 0.094 & 0.098 & 0.156 & 0.091 & 0.083 & 0.154 \\
\hline & & $-3.09 \%$ & $1.03 \%$ & $60.8 \%$ & $-6.2 \%$ & $-14.4 \%$ & $58.8 \%$ \\
\hline & & \multicolumn{3}{|c|}{ Uniform } & \multicolumn{3}{|c|}{ Hybrid } \\
\hline reduction & $0 \%$ & $15 \%$ & $30 \%$ & $45 \%$ & $15 \%$ & $30 \%$ & $45 \%$ \\
\hline \multirow{2}{*}{$\begin{array}{l}\text { Number } \\
\text { of faces }\end{array}$} & \multirow{2}{*}{124} & 1150 & 122 & 110 & 131 & 110 & 72 \\
\hline & & $17.33 \%$ & $-1.61 \%$ & $-11.29 \%$ & $5.64 \%$ & $-11.3 \%$ & $-41.9 \%$ \\
\hline \multirow{2}{*}{$\begin{array}{c}\text { Max. } \\
\text { deviation }\end{array}$} & \multirow{2}{*}{1.57} & 1.42 & 0.76 & 1.06 & 0.72 & 0.95 & 0.55 \\
\hline & & $-9.55 \%$ & $-51.6 \%$ & $-32.5 \%$ & $-54.14 \%$ & $-39.5 \%$ & $-65 \%$ \\
\hline \multirow{2}{*}{$\begin{array}{c}\text { Min. } \\
\text { deviation }\end{array}$} & \multirow{2}{*}{-0.65} & -0.59 & -1.54 & -0.67 & -0.47 & -0.72 & -0.64 \\
\hline & & $-9.23 \%$ & $136.9 \%$ & $3.07 \%$ & $-27.7 \%$ & $10.8 \%$ & $-1.5 \%$ \\
\hline \multirow{2}{*}{$\begin{array}{c}\text { Std. } \\
\text { deviation }\end{array}$} & \multirow{2}{*}{0.097} & 0.104 & 0.098 & 0.097 & 0.088 & 0.098 & 0.098 \\
\hline & & $7.21 \%$ & $1.03 \%$ & $0.0 \%$ & $-9.3 \%$ & $1.03 \%$ & $1.03 \%$ \\
\hline
\end{tabular}

The next step is smoothing of triangle meshes which was performed through three different criteria: local, global and boundary smoothness. The smoothing process assumes 0 (zero) value for no smoothing and 10 value for maximum smoothing with results reported in Fig. 7. As seen in Fig. 7, the outcome of the results shows a declining trend for the maximum deviation. The results for the minimum deviation are slightly varying as compared to maximum deviation. 
The max. deviation values begins from 0 and then stabilizes at 6 . One value for the minimum deviation shows a significant variation for the factor 3 , which is a particular extreme point present in the mesh file without any effect in the analysis of the results.

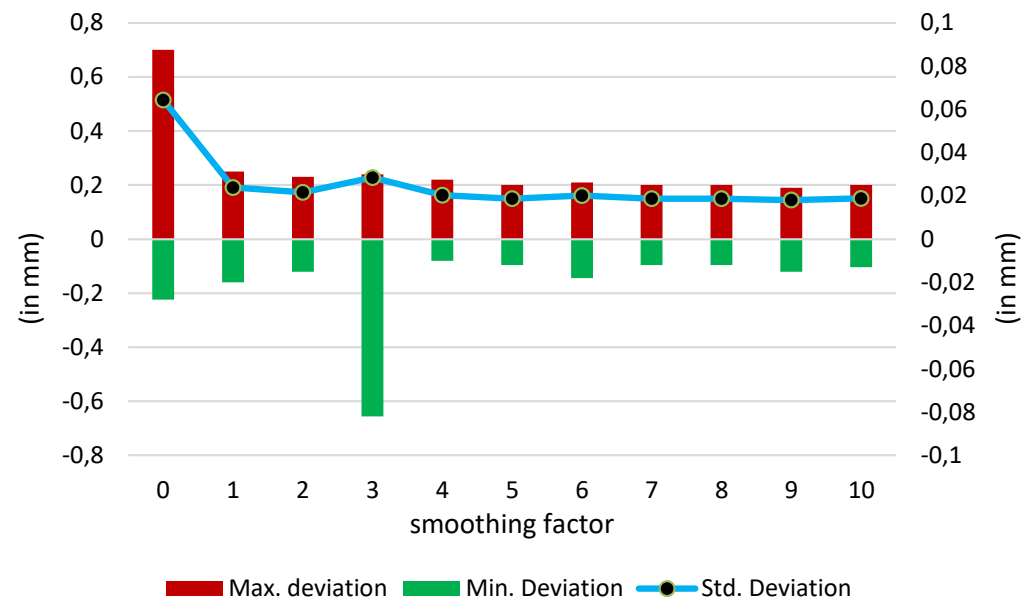

Fig. 7. Plot for smoothing factor effect

The used add-in directly converts the triangle mesh file to a solid model through the Automatic Creation command. Also, the guide creation command is sometimes used to generate sub-meshes which directly fit the surface. The final step performed was generation of part-surface by means of surface command with an increase of surface detail factor from 0 to 20. The default factor value used by software was 10 . Consequently, two mesh files were considered, one with best results of filtering and smoothing and another mesh without filtering or smoothing effects (curvature filter $30 \%$ and smoothing factor 4). Five different conditions were selected $(2,6,10,14$, 18) and the result depicts how the surface accuracy increases with the increment of the detail factor.

\section{Result and discussion}

For investigation on the real implications of the proposed methodology for producing accurate models, comparison of the SolidWorks model and the CATIA model with the actual model was performed. The developed prosthetic models using both software are shown in Fig. 8. The comparison of different models was implemented using a computer controlled CMM (INSPECS RUBY 564 CMM). For effective comparison, 3-2-1 rule was used to perform suitable alignment. The importance of 3-2-1 rule is that it restricts six degrees of freedom available for the models in space that helps in effective alignment. The next step is to measure the external surface of prosthesis socket physical model in sixty random positions using 


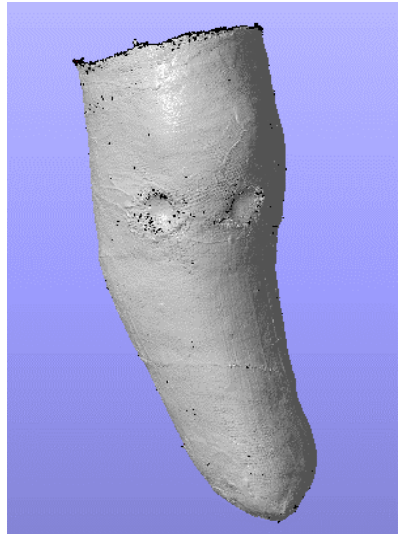

(a)

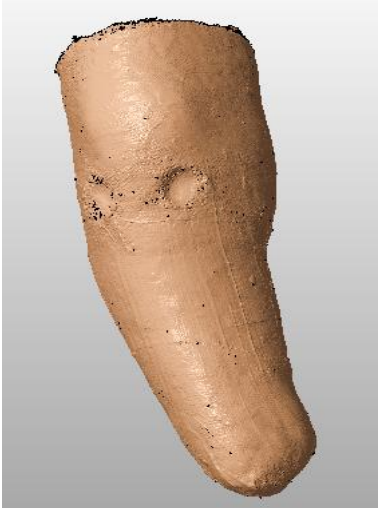

(b)

Fig. 8. Developed model using (a) CATIA V5 (b) Solidworks software

probe tip of $2 \mathrm{~mm}$ diameter. Lastly, the deviation of the measured values of the actual model were compared with the digital model of RE. The nominal values at different original model points were consider as reference values and comparative results for the six dissimilar 3D models were reported in Table 4. The result shows that surfaces developed by applying extra-fine command in both the software have a comparable accuracy (85\% CATIA against $81.7 \%$ points for Solidworks within the tolerance zone of $\pm 0.2 \mathrm{~mm}$ ). One significant difference reported in comparison of both software kinds was in the model development using default parameters. The Solidworks result is better than the CATIA result for default value, but it cannot be linked with the inaccuracy of the CATIA, it is because of higher extent of the automatic commands employed in Solidworks (ScanTo3D).

Table 4.

Comparison of the models

\begin{tabular}{|l|c|c|c|c|c|c|}
\hline & \multicolumn{3}{|c|}{ CATIA } & \multicolumn{3}{c|}{ Solidworks } \\
\hline $\begin{array}{c}\text { Coarse } \\
\text { (default) }\end{array}$ & fine & $\begin{array}{c}\text { Very Fine } \\
\text { (mesh H) }\end{array}$ & $\begin{array}{c}\text { Coarse } \\
\text { (default) }\end{array}$ & fine & Very Fine \\
\hline Filtering process & None & $\begin{array}{c}\text { Homogeneous } \\
30 \%\end{array}$ & $\begin{array}{c}\text { Homogeneous } \\
30 \%\end{array}$ & None & $\begin{array}{c}\text { Curvature } \\
30 \%\end{array}$ & $\begin{array}{c}\text { Curvature } \\
30 \%\end{array}$ \\
\hline Smoothing process & None & None & Single effect (0.5) & None & None & $10 \%$ \\
\hline Optimization process & none & none & yes & none & none & none \\
\hline Measured points & 60 & 60 & 60 & 60 & 60 & 60 \\
\hline Points out of tolerance & 33 & 25 & 9 & 20 & 14 & 11 \\
\hline Efficiency & $45 \%$ & $58.33 \%$ & $85 \%$ & $66.67 \%$ & $76.67 \%$ & $81.67 \%$ \\
\hline Max. deviation & 0.517 & 0.647 & 0.302 & 0.287 & 0.289 & 0.297 \\
\hline Min. deviation & -0.669 & -0.517 & -0.408 & -0.447 & -0.421 & -0.403 \\
\hline Std. deviation & 0.237 & 0.216 & 0.145 & 0.152 & 0.148 & 0.149 \\
\hline
\end{tabular}


The prime objectives of this study includes the assessment of the accuracy of digital 3D models developed by RE procedure and determination of the key factors which influence the freeform, dimensional and geometric accuracy. The investigation of absolute accuracy is very problematic since the only reference available for a user is the original model. However, the digital and the actual models were used to compare the dimensional deviations at each corresponding points. The Hausdorff-distance criteria were used for determining the differences in the two models.

The methodology presented in this paper shows that inexperienced users have an extra advantage in working on instinctive and automated tools like ScanTo3D and a digitized shape editor. On the contrary, a skilled user can help in improving the quality and accuracy of digital models generated using vigilant selection of different point processing parameters using a variety of CAD tools. The software used in this study have better flexibility in selecting different point processing parameters. The accuracy obtained for the developed model in this study is in accordance with published literature results [6], for the use in medical applications and in FEM analysis.

\section{Conclusion}

The present study proposed two unified solutions using different CAD methodologies for modelling and analysing a freeform surface from a raw unorganized point cloud. In the first approach, the digital model was generated with default settings of the used software. For second approach, the developed digital model was based on the user's expertise to achieve an upgraded and enhanced surface model. The proposed methodologies are useful in capturing the original surface model accurately and improving the conventional reverse engineering process appropriately. There are different commercial software packages available in market that provide a variety of options to the users to select the best among them.

Numerous efforts have been made to control filtering, mesh smoothing, segmentation and surface generation parameters, errors and inaccuracies. However, the results found were not satisfactory. Therefore, a step by step alternating RE process with emphasis on using commercial software tools is proposed in this study that can also develop accurate digital surface models compared to conventional one-step point cloud processing. The result obtained for developed digital model is in accordance with prosthetic and orthotic practice and FEM analysis.

Manuscript received by Editorial Board, June 18, 2016; final version, September 27, 2016.

\section{References}

[1] M. Sokovic and J. Kopac. Re (reverse engineering) as necessary phase by rapid product development. Journal of Materials Processing Technology, 175(1):398-403, 2006. 
[2] E. Solaberrieta, O. Etxaniz, R. Minguez, J. Gorozika, L. Barrenetxea, and E. Sierra. Virtual prouction of dental prostheses using a dental virtual articulator. International Journal on Interactive Design and Manufacturing (IJIDeM), 9(1):19-30, 2015.

[3] M. Fantini, F. De Crescenzio, and L. Ciocca. Design and rapid manufacturing of anatomical prosthesis for facial rehabilitation. International Journal on Interactive Design and Manufacturing (IJIDeM), 7(1):51-62, 2013.

[4] K.D. Creehan and B. Bidanda. Computer-aided reverse engineering of the human musculoskeletal system. Virtual and Physical Prototyping, 1(2):83-91, 2006.

[5] R. Pandey and L.N. Pattanaik. A fuzzy qfd approach to implement reverse engineering in prosthetic socket development. International Journal of Industrial and Systems Engineering, 17(1):1-14, 2014.

[6] Y.P. Lin, C.T. Wang, and K.R. Dai. Reverse engineering in CAD model reconstruction of customized artificial joint. Medical Engineering \& Physics, 27(2):189-193, 2005.

[7] A. Amin, S. Suresh, A. Sanghrajka, S.R. Cannon, T.W.R. Briggs, and P. Unwin. Custommade endoprosthetic reconstruction of the distal humerus for non-tumorous pathology. Acta orthopaedica Belgica, 74(4):446-450, 2008.

[8] Y. Jun and S. Park. Polygon-based 3D surgical planning system for hip operation. International Journal of Precision Engineering and Manufacturing, 12(1):157-160, 2011.

[9] V.K. Pathak, A.K. Singh, M. Sivadasan, and N.K. Singh. Framework for automated GD\&T inspection using 3D scanner. Journal of The Institution of Engineers (India): Series C, pages $1-9,2016$.

[10] M. Dujovny, R. Evenhouse, C. Agner, F.T. Charbel, L. Sadler, and D. McConathy. Preformed prosthesis from computed tomography data: Repair of large calvarial defects. In E.C. Benzel and S.S. Rengachary, editors, Calvarial and Dural Reconstruction, pages 77-88. American Association of Neurological Surgeons, Park Ridge, III, 1999.

[11] Materialise, case: Modeling and design of a custom made cranium implant for large skull reconstruction before a tumor removal, http://www.materialise.com/materialise/view/en/421308, 2001.

[12] L.M. Galantucci, G. Percoco, and U. Dal Maso. Coded targets and hybrid grids for photogrammetric 3d digitisation of human faces. Virtual and Physical Prototyping, 3(3):167-176, 2008.

[13] J. Roca-Pardiñas, H. Lorenzo, P. Arias, and J. Armesto. From laser point clouds to surfaces: Statistical nonparametric methods for three-dimensional reconstruction. Computer-Aided Design, 40(5):646-652, 2008.

[14] J-P. Pernot, G. Moraru, and P. Véron. Repairing triangle meshes built from scanned point cloud. Journal of Engineering Design, 18(5):459-473, 2007.

[15] B.R. Barbero. The recovery of design intent in reverse engineering problems. Computers \& Industrial Engineering, 56(4):1265-1275, 2009.

[16] J. Kofman and K. Borribanbunpotkat. Hand-held 3d scanner for surface-shape measurement without sensor pose tracking or surface markers. Virtual and Physical Prototyping, 9(2):81-95, 2014.

[17] V.K. Pathak and A.K. Singh. Alignment based inspection framework for additive manufactured parts. In C.S. Mandal, D.K. and Syan, editor, CAD/CAM, Robotics and Factories of the Future: Proceedings of the 28th International Conference on CARs \& FoF 2016, pages 335-344. Springer, 2016.

[18] D. Gibson. Parametric feature recognition and surface construction from digital point cloud scans of mechanical parts. Master's thesis, University of Oklahoma, 2004. 


\title{
Zastosowanie zintegrowanych metod inżynierii odwrotnej do kontroli dokładności wykonania obiektów o dowolnych kształtach
}

\author{
Streszczenie
}

Narzędzia wspomagania komputerowego pomagają skrócić lub wyeliminować powtarzające się wielokrotnie zadania $\mathrm{w}$ procesie redukowania różnic pomiędzy rzeczywistym produktem a jego modelem cyfrowym. Ich zastosowanie pomaga realizować obiekty o dowolnych kształtach, takie jak produkty dopasowane indywidualnie, przeznaczone do ścisłego współdziałania z ciałem człowieka. Opracowanie modeli podobnego rodzaju stanowi dla inżynierii odwrotnej wyzwanie nieporównywalnie trudniejsze od tego, jakim jest tworzenie modeli o prostych formach geometrycznych. Biorąc powyższe pod uwagę, autorzy zaproponowali alternatywną drogę tworzenia dokładniejszych modeli trójwymiarowych. W celu realizacji tego zadania trójwymiarowe chmury punktów są przetwarzane drogą filtracji, segmentacji, wygładzania siatki i generacji powierzchni. Zastosowane procesy przetwarzania pomagają przekształcić początkowy nieuporządkowany zbiór danych w model trójwymiarowy, wpływając jednocześnie na jakość tego modelu. W pracy zaproponowano kompromis pomiędzy osiąganiem najlepszej dokładności przy dopuszczalnych odchyłkach a zmniejszeniem obciążenia komputera i czasu przetwarzania danych. Rozważono realistyczny, nietrywialny przypadek modelu o złożonym kształcie - trzonu protezy kończyny. Dokładność uzyskanego modelu okazała się wystarczająca do zastosowań medycznych oraz do celów analizy MES. 